\title{
Ultrasonic Identification of Weld Defects Made by Electrofusion Welding on Plastic Pipelines
}

Martin Faturík, Miloš Mičian, Radoslav Koňár

University of Žilina, Univerzitná 1, Department of Mechanical Engineering Technologies; E-mail: martin.faturik@fstroj.uniza.sk,milos.mician@fstroj.uniza.sk,radoslav.konar@fstroj.uniza.sk

In this article is described, how can ultrasonic method Phased Array be used for inspection of weld joints made by electrofusion welding on plastic pipelines. For purpose of testing and to develop a proper setup, several artificially made defects were created in the weld area to verify, if this method can be successfully used for this application, since standards for testing of plastic pipelines have no specific regulation for this method. Therefore we are trying to propagate this method for gas and water transport industry, because it can severely reduce risks of accidents caused by unidentified defects, which can occur in welded joints.

Keywords: ultrasonic defectoscopy, phased array, plastic pipelines, gas industry

\section{Acknowledgement}

Article was created within project solution VEGA: 1/0836/13, KEGA: 034ZU-4/2015 a KEGA: 014ZU-4/2015.

\section{References}

[1] KOVÁČIK, M., HYŽA, R. (2013). Ultrazvuková skúška časti obvodového zvaru čpavkovej tlakovej nádoby technikami Phased Array a TOFD. [Online] 2013. [Date: 21. 04 2013.] http://www.ssndt.sk/files/odborne/PA\%20a\%20TOFD\%20na\%20cpavku.pdf.

[2] KOVÁČIK, M. (2010). Skúšanie materiálov ultrazvukom. Bratislava : s.n.,

[3] MARTANČÍK, B. (2012). Výskum diagnostiky defektov pomocou nových ultrazvukových metód TOFD a Phased Array a vplyv na životnost' zváraných konštrukcií. Bratislava: Slovenská technická unverzita v Bratislave, s. 151, dizertačná práca.

[4] OBRAZ, J. (1989). Zkoušení materiálu ultrazvukem. Praha : SNTL Nakladatelství technické literatury, s. 464. ISBN 80-03-00097-1.

[5] OLYMPUS. (2004). Introduction to Phased Array Ultrasonic Technology Applications. Waltham, MA : Olympus NDT, s. 351. ISBN 0-9735933-0-X.

[6] OLYMPUS. (2012). Phased Array Testing Basic Theory for Industrial Applications. 2nd ed. Waltham, MA : Olympus NDT, s. 113. DMTA-20003-01EN.

[7] LOYDA, M., ŠPONER, V.. ONDRÁČEK, L., a kol. (2001). Svařování termoplastů. Praha. Uno, 2001. ISBN 80-223-6603-6

[8] MORAVEC, J., BRADÁČ, J., BERAN, D., NOVÁKOVÁ, I. (2014). The Impact of Thermal Cycles of Superheated Steam on Pipes Material of By-Pass of Steam and Gas-Steam. In: 23rd International Conference on Metallurgy and Materials, Metal 2014, Brno, ISBN 978-80-87294-52-9.

[9] SEJČ, P., BIELAK, R., ŠVEC, P., ROŠKO, M. (2006). Computer simulation of heat affected zone during MIG brazing of zinc-coated steel sheets. In Kovové materiály. Metallic materials. Roč. 44, č. 4, s.225-234. ISSN 0023-432X.

[10]MEŠKO, J., ZRAK, A., MULCZYK, K., SZYMON, T. (2014). Microstructure analysis of welded joints after laser welding. In: Manufacturing technology: journal for science, research and production. - ISSN 1213-2489. Vol. 14, no. 3, s. 355-359.

[11]NORBERT, R., MEŠKO, J., ZRAK, A. (2014). Technology of laser forming. In: Manufacturing technology: journal for science, research and production. - ISSN 1213-2489. - Vol. 14, no. 3, s. 428-431. 